\title{
Erratum to: Upregulation of arginase-II contributes to decreased age-related myocardial contractile reserve
}

\author{
Mehnaz Khan · Jochen Steppan - Karl H. Schuleri - Sungwoo Ryoo • \\ Eric Tuday • Lukasz Bugaj - Lakshmi Santhanam - Tal Berkowitz • \\ Daniel Nyhan · Artin A. Shoukas · Dan E. Berkowitz
}

Published online: 5 October 2012

(c) Springer-Verlag Berlin Heidelberg 2012

Erratum to: Eur J Appl Physiol (2012) 112:2933-2941

DOI 10.1007/s00421-011-2257-9

In the original publication of the article, an author's name has been inadvertently published without the initial. The correct author name should be Karl H. Schuleri.

The online version of the original article can be found under doi:10.1007/s00421-011-2257-9.

M. Khan - J. Steppan - S. Ryoo - L. Santhanam - T. Berkowitz ·

D. Nyhan · D. E. Berkowitz $(\square)$

Department of Anesthesiology and Critical Care Medicine,

Johns Hopkins University Medicine, Tower 711, 600 N Wolfe St.,

Baltimore, MD 21287, USA

e-mail: dberkowi@bme.jhu.edu

K. H. Schuleri

Department of Medicine, Johns Hopkins University Medicine,

600 N Wolfe St., Baltimore, MD 21287, USA

E. Tuday - L. Bugaj - A. A. Shoukas - D. E. Berkowitz

Department of Biomedical Engineering,

Johns Hopkins University Medicine, 600 N Wolfe St.,

Baltimore, MD 21287, USA 